\title{
Discursos sobre a eficácia educacional: encontros e desencontros entre técnicos em educação e professores (Brasil, décadas de 1950 a 1970) ${ }^{1}$
}

\section{Discourses on educational efficiency: proximities and distances between educational technicians and teachers (Brazil, 1950s to 1970s)}

\author{
Rosario Genta Lugli² \\ Vivian Batista da Silva ${ }^{3}$
}

\begin{abstract}
RESUMO
Neste texto articulam-se resultados de investigações sobre a produção e circulação de conhecimentos pedagógicos. Comparecem aqui três fontes diferenciadas na produção desses saberes: a documentação dos Congressos Nacionais de Professores Primários; discursos dos Centros Regionais de Pesquisas Educacionais; e textos dos manuais pedagógicos, usados nas escolas de formação do magistério primário. Esses materiais são especialmente úteis para compreender como os apelos de racionalização do trabalho docente com ênfase nos métodos e técnicas de ensino, característicos do discurso educacional entre meados do século XX e a década de 1970, são construídos
\end{abstract}

DOI: $10.1590 / 0104-4060.36640$

1 O presente artigo resulta da articulação de duas pesquisas desenvolvidas em nível de doutorado (O Trabalho Docente no Brasil: os discursos dos Centros Regionais de Pesquisa Educacional e das Entidades Representativas do Magistério (1950-1971), 2002 e Saberes em viagem nos manuais pedagógicos: construções da escola em Portugal e no Brasil (1870-1970), 2006), ambas com apoio financeiro da FAPESP.

2 Universidade Federal de São Paulo. Guarulhos, São Paulo. Brasil. Campus Guarulhos (Unidade Provisória). Escola de Filosofia, Letras e Ciências Humanas, Rua do Rosario, 382 (antigo 117), Bairro Macedo. CEP: 07111-080.

3 Universidade de São Paulo, São Paulo, São Paulo, Brasil. Faculdade de Educação. Av. da Universidade, $\mathrm{n}^{\mathrm{o}}$ 308, Cidade Universitária. CEP: 05508-040. 
em instâncias diversas do campo educacional brasileiro. Nessa perspectiva, é possível evidenciar as disputas envolvidas nessa ênfase na dimensão técnica do ensino, entre os agentes localizados em diferentes posições: autoridades oficiais do Estado, pesquisadores e professores primários. No entrecruzamento desses textos é notável a progressiva adesão aos valores vindos de uma visão técnica do ensino como verdades inquestionáveis e a constituição da "teoria" como um tipo diferenciado de conhecimento pedagógico associado à maior legitimidade dos "técnicos em educação", constituídos simultaneamente pelos vínculos com a Universidade e com o Estado.

Palavras-chave: conhecimento pedagógico; tecnicização do ensino; história da educação.

\begin{abstract}
This article combines the results of research works on the production and circulation of pedagogical knowledge. We use here three different sources from the creation of such knowledge: documents from the National Reunions of Elementary Teachers; speeches from the Regional Centers for Educational Research and the textbooks used in the initial preparation of elementary teachers. These three sets of documents are particularly useful for the understanding of the arising and settlement of work rationalization on teaching activities emphasizing their methods and procedures that are characteristic of the Brazilian educational speech between the 1950s and the 1970s as well as the way they were built in various branches of the Brazilian educational field. From that point of view, it is possible to identify the disputes over the definition of technical dimensions of teaching among the agents located in different spots of the educational field, and sometimes simultaneously in more than one position: official state authorities, educational researchers and primary teachers. It is remarkable, when these discourses are compared, the increasing power of a technical view of teaching as unquestionable truth, as well as the constitution of the "theory" as a separate kind of pedagogical knowledge associated to the increasing legitimacy of the "educational technicians", that were simultaneously linked to the university and to the state.

Keywords: educational knowledge; teaching technicality; education history.
\end{abstract}


No ensino, a determinação de qual seja essa "melhor maneira" dependerá, em cada caso, do discernimento e da capacidade imaginativa e crítica do professor, sobrepondo-se à rotina e abrindo novos caminhos, mais consentâneos e racionais, para atingir os objetivos visados...

Luís Alves de Matos. Sumário de didática geral. RJ: Aurora, 1957, p. 14.

O trecho acima transcrito integrou um manual largamente difundido nas escolas de formação do magistério no Brasil e assinalou uma preocupação comum à época de sua publicação, qual seja, a de encontrar os "recursos e procedimentos adotados em aula" para que, "em caminhos mais consentâneos e racionais", sejam atingidos os objetivos do ensino (MATOS, 1957, p. 14). Suas palavras ilustraram como, ao longo das décadas de 1950 a 1970, foram sendo incorporadas novas exigências aos professores. Não apenas os livros de formação, como também as orientações do Estado, as produções científicas e das próprias organizações de docentes primários afirmaram a necessidade de racionalizar cada vez mais o trabalho da sala de aula. Se quiséssemos resumir a imagem de "bom" professor desse momento, poderíamos descrevê-la como a de um profissional que sabe planejar, ordenar os conteúdos, usar os métodos e as técnicas didáticas mais eficazes. Denominado de "tecnicização do ensino" (MACHADO, 1980), esse processo integrou a configuração do modelo de escola moderna, construído em diversas partes do mundo desde finais do século XIX (NÓVOA; SCHRIEWER, 2000), institucionalizando modos de trabalho específicos e familiares a nós. Convém lembrar que a instituição começou a se desenvolver em diversas partes do mundo em finais do século XIX, sob a responsabilidade do Estado, no intuito de se estender a toda população de forma obrigatória, leiga e gratuita (NÓVOA; SCHRIEWER, 2000). A sua força é medida não apenas pela existência de mais de um século e meio, como também pela permanência de um modelo praticamente inquestionável, com classes graduadas agrupando os alunos; professores atuando individualmente junto a uma turma de estudantes, com perfil de generalistas nos primeiros níveis de ensino e com perfil de especialistas nos graus seguintes; com uma arquitetura que lhe é característica; com tempos determinados para cada tipo de atividade dos alunos e dos professores (NÓVOA, 1995). Essa organização não é tomada apenas como a melhor, mas como a única via possível de ensino (TYACK, 1974). Como afirmam Correia e Gallego (2004, p. 9), "é nesse tipo de escolas que se desenvolveu e aperfeiçoou a nova racionalidade pedagógica, organizacional e temporal" e que, conforme discutiremos neste artigo, teve em meados do século XX uma ênfase específica, pelo menos no caso brasileiro, quando as atenções se voltaram para o aperfeiçoamento das técnicas e métodos de ensino. 
A vocação para o magistério e as tarefas da escola, temas de destaque nos anos finais do século XIX e início do século XX, e o aluno, tema recorrente entre as décadas de 1920 e 1930, deixaram de ser tão centrais na discussão e orientação pedagógica (SILVA, 2005), em meio aos apelos de racionalização da docência, marcando as disputas entre os valores tradicionais e os modernizantes no campo educacional brasileiro (LUGLI, 2002).

$\mathrm{Na}$ análise aqui proposta comparecem três fontes diferenciadas na produção do conhecimento no campo educacional - a primeira delas é constituída pela documentação dos Congressos Nacionais de Professores Primários, realizados por associações de professores a partir de 1953 a cada dois anos; a segunda fonte corresponde ao conjunto dos discursos dos Centros Regionais de Pesquisas Educacionais (CRPEs), que atuaram em cinco estados brasileiros (MG, SP, RS, BA e PE) entre 1955 e 1975 (LUGLI, 2002) propondo a investigação científica baseada na sociologia do ensino e divulgada para os administradores do sistema educacional; finalmente, a terceira fonte diz respeito aos manuais pedagógicos, editados e usados em várias cidades do país desde finais do século XIX para dar conta da formação inicial de docentes (SILVA, 2005). Trata-se, portanto, de uma análise que articula diferentes pesquisas (LUGLI, 2002 e SILVA, 2005) acerca da produção e circulação de conhecimentos entre os professores, cada uma delas envolvendo diferentes lugares de produção desses saberes, tanto no que se refere às suas naturezas e aos seus espaços de distribuição no território brasileiro quanto às suas condições de escrita. Em nosso entender, essas três dimensões permitem apreender as disputas envolvidas no campo educacional, entre os agentes localizados em diferentes posições: autoridades oficiais de ensino, pesquisadores em educação e docentes - vale observar que estas categorias não constituem grupos separados, podendo uma autoridade do ensino (como frequentemente era o caso) ser também docente, autor de manuais didáticos ou pesquisador em educação. O critério para a análise foi o lugar da produção desse discurso, bem como seu conteúdo - é nessa medida que se podem apreender seus possíveis efeitos sociais.

Os fundamentos desse esforço concentram-se naquilo que Denice Catani (2000) assinala como sendo a produção de distâncias e vizinhanças no espaço dos educadores, ou seja, o reconhecimento de que essa diversidade dos lugares de escrita não foi a expressão pacífica de ideias, pois decorreu de aproximações e embates em torno do projeto nacional de ensino. Assim, embora tenha havido um consenso acerca do que se esperou da escolarização, foi inegável o fato de que as diferentes posições ocupadas pelos especialistas em educação e pelos professores primários geraram divergências nos modos pelos quais a educação foi pensada e dada a ler. Na comparação entre os discursos dos Congressos, dos CRPEs e dos manuais para professores percebe-se que os pensamentos 
não circularam invariavelmente como cópias das produções dos níveis mais legítimos do campo educacional. Ressalte-se que trabalhamos aqui com textos propostos para a formação inicial, os manuais pedagógicos; com textos dos CRPEs, que pretendiam modificar as práticas daqueles professores já em serviço e, finalmente, com os textos que, mesmo sendo produzidos por instâncias de representação coletiva, deram luz a um pensamento "próprio" dos professores primários a respeito das mudanças que o campo educacional vivia naquele momento. Isso nos conduz a perguntar sobre as formas de interação possíveis entre os agentes desse espaço, bem como a analisar de que modo os discursos produzidos por cada um desses grupos representaram seus lugares no campo e produziram, nessa perspectiva, uma concepção sobre educação, instaurando modos ideais de conceber a profissão docente.

Considerar esse universo de fontes permite, portanto, compreender como se construíram os discursos que enfatizaram a racionalização dos métodos e técnicas do ensino e a instituíram como a principal característica do bom professor. É nesse sentido que se examina a produção da cultura profissional docente (PERRENOUD, 1993), entendida enquanto um amplo conjunto de práticas, dentre as quais estão as tarefas cotidianas em sala de aula, a convivência com os alunos e colegas de trabalho, a partilha de uma identidade comum, enfim, um modo de conceber e viver a profissão que se configura, em plano individual, como um habitus (BOURDIEU, 1996) característico dos professores. A construção dessas modalidades de ação e percepção articula-se com a produção e circulação dos conhecimentos pedagógicos, pois, ao se destinarem à formação e aperfeiçoamento do ensino, eles contribuem para instaurar novas características no conjunto de práticas que aqui se chama cultura profissional. Em outras palavras, os saberes educacionais são dados a ler para delimitarem representações (CHARTIER, 1990) acerca das qualidades de excelência do exercício profissional, contribuindo para incorporar nos indivíduos os gestos tidos como mais necessários ou convenientes e, antes de mais nada, configurando uma imagem social das características desejáveis para a profissão. No Brasil, a história da elaboração e divulgação de textos pedagógicos teve um de seus períodos de maior efervescência nas décadas de 1950 e 1960, quando se observou uma mudança significativa nas imagens constituintes da representação profissional. Nesse momento acrescentaram-se aos valores tradicionais da docência os que destacavam as virtudes morais e a vocação para o magistério, a necessidade de inovação e de adaptação a uma sociedade onde se queria investir na industrialização, o que significou naquele momento conceber o ensino como técnica cientificamente fundamentada. Proposições dessa natureza incentivaram, por exemplo, a produção de obras nacionais, estrangeiras ou traduzidas sobre Psicologia, Filosofia, História, Sociologia, além da legislação escolar, de programas para o ensino de 
disciplinas, de revistas especializadas, de manuais para professores, entre outros. E, se o conjunto das fontes aqui delimitadas permite apreender essa dinâmica, convém atentar para as condições de produção de cada uma delas, assinalando suas especificidades e seus conteúdos. A seguir, o presente artigo trata de cada um dos conjuntos de fontes aqui consideradas, ou seja, analisa primeiramente as Atas dos Congressos Nacionais de Professores Primários ocorridos durante a década de 1950, para depois examinar as produções dos Centros Regionais de Pesquisas Educacionais e, finalmente, os conteúdos presentes nos manuais pedagógicos publicados no período em pauta. $\mathrm{O}$ intuito, como já assinalamos, é entender como esses discursos participam da construção de um modo de ser professor pautado na racionalização do ensino.

\section{A voz dos professores primários em seus Congressos Nacionais}

Durante a década de 1950, as associações docentes estaduais começaram a se articular em nível nacional por meio de Congressos Nacionais de Professores Primários (LUGLI, 2002). Essas reuniões representaram um importante fórum de discussão, bem como um espaço de lutas entre as diversas entidades para o estabelecimento de um modelo associativo nacional, o qual passou a se configurar já desde o primeiro evento. Realizado na Bahia em 1953, ele foi dedicado ao debate de uma série de temas relativos à profissão, entre os quais se contavam questões de formação, métodos de ensino, assistência aos alunos desfavorecidos, aposentadoria etc. (FERREIRA JR., 1998). Entre as recomendações finais deste primeiro Congresso encontravam-se várias indicações que revelavam o projeto de uma organização nacional em defesa do magistério, numa tentativa de articular as associações de professores primários estaduais. Tentava-se superar os efeitos decorrentes da "dualidade de sistemas" educacionais (AZEVEDO, 1976) que se instituíra desde a Constituição de 1890 no país - ou seja, como o ensino primário ${ }^{4}$ estava exclusivamente a cargo dos estados, deu-se origem a sistemas diferenciados e independentes nesse nível de ensino, o que terminou por gerar associações docentes limitadas ao nível estadual.

O próprio movimento de articulação nacional das entidades de professores, portanto, colocava em primeiro plano a tensão entre os princípios de descentralização e centralização administrativa no ensino, que, vale lembrar, estavam

4 A Lei Orgânica do Ensino Primário, vigente desde 1946, é a primeira a tentar regular, em nível federal, esse grau de escolaridade. 
sendo extensamente debatidos nesse período nas instâncias legislativas nacionais, tendo em vista o projeto da Lei de Diretrizes e Bases que seria promulgada em 1961 (RIBEIRO, 2000). Os professores primários reunidos nos I e II Congressos Nacionais não permaneceram alheios a este debate - o tema da centralização ou descentralização federativa do ensino fundamental foi uma das discussões principais desses eventos, segundo observação de Amarilio Ferreira Jr. (1998). Nesse contexto, a tese da "federalização do ensino primário", que propunha uma extrema centralização administrativa, parece ter causado polêmica, conforme observações isoladas nas atas de reuniões de diretoria da SUPP (Sociedade Unificadora do Professorado Primário da Bahia).

Segundo Antonino Rocha (1955, p. 2), os temários dos Congressos tratavam de temas ligados ao ensino, mas não diretamente ao professor primário: "o Professorado, como sempre, esqueceu-se de si mesmo e cuidou demais dos problemas do ensino". O objetivo último dos Congressos seria o de solucionar os problemas do ensino primário, o que só seria obtido quando os professores primários deixassem de ser estaduais para se tornarem nacionais, os programas da escola primária fossem padronizados, o livro didático unificado, quando houvesse assistência ao professor do interior e das zonas suburbanas da capital e se proporcionasse ao professor "meio de vida condizente com a sua função, de modo a não desviá-lo de seu mister para cobrir necessidades imprescindíveis" (ROCHA, 1955, p. 2). Todas essas sugestões encontravam-se inter-relacionadas, constituindo a proposta de federalização do ensino primário, que implicaria na centralização pelo Ministério da Educação das contratações e remoções para as escolas de todo o país "de acordo com as necessidades do ensino, sem política, sem pistolão e sem o prestígio dos coronéis." (ROCHA, 1955, p. 4). A federalização era proposta não só como forma de solucionar a interferência da política local na administração do ensino; também era pensada como um meio de proporcionar aos professores uma certa mobilidade para compensar a inexistência de uma carreira. Em palavras proferidas naquela ocasião:

Unificar o Professorado Primário no Brasil é abrir novos horizontes à instrução popular e facultar ao professor o desintoxicamento causado por um só ambiente, durante toda a vida funcional. É verdade que há muito o Professor Primário, já vencido, cansado pelas injustiças sofridas, traumatizado pelas preterições, não deseja outra coisa senão a aposentadoria, para descansar ou morrer. Mas existe o Professorado Novo, cheio de ideais, que completa a falência de seu curso com a aquisição de livros, estudos especializados, que acompanha através de noticiários o avanço educacional no mundo de hoje, que tem vontade de se afastar um pouco 
do meio a que the conduzira um concurso inteligentemente feito, pago com uma escola de praia deserta, que se unificado, o Professor poderia ser removido para uma escola em outro estado, em uma cidade de hábitos diferentes, de meio cultural diferente, e até de apoio diferente ao professor, para depois de tudo isto, retornar ao seu Estado cheio de glórias para sua gente (ROCHA, 1955, p. 2-3).

A proposta da federalização coloca em jogo as antinomias básicas do discurso educacional do período: os aspectos regionais contrapostos aos nacionais e a modernidade educacional à tradição, na eloquente imagem do professor velho e cansado que só deseja morrer frente ao professor jovem, que realiza "estudos especializados" e toma contato com o "avanço educacional". Observe-se que, nessa idealização dos termos da reforma educativa, a modernização não corresponde somente ao jovem, ao novo, também se trata de estabelecer uma estrutura de tipo burocrática que liberaria os professores das amarras políticas locais e permitiria intervenções de caráter técnico no sistema de ensino e, portanto, mais legítimas do ponto de vista dos agentes do campo educacional.

Ora, a esta idealização das competências técnicas com relação à modernidade educativa, compreendida como eficiência do trabalho docente, contrapõem-se, no mesmo texto, observações bastante virulentas quanto à capacidade de intervenção dos técnicos educacionais, ou seja, dos especialistas com formação acadêmica que trabalhavam na produção de estudos e materiais de orientação das tarefas realizadas pelos professores nas escolas. Essas críticas foram notáveis no trecho que Antonino Rocha dedicou à padronização do programa de ensino:

Os técnicos são figuras decorativas e nada entendem, sendo-lhes completamente desconhecidos o ensino, as escolas e seus problemas. Conheço técnicos que nunca foram a uma escola e vivem burocraticamente informando papéis e verificando o meio de perseguir o Professor, e assim continuam os programas oficiosos ou oficiais, sendo o melhor de todos esses o aplicado pelo professor, como tenho observado (ROCHA, 1955, p. 4-5, grifos nossos).

Note-se que a grande crítica do texto aos chamados "técnicos do ensino" foi a sua distância com relação à realidade da sala de aula, vivida cotidianamente pelos professores. Este tipo de comentário, presente em outras fontes, permite entrever um choque de valores no campo educacional, que opunha a prática (vivida pelos professores) à teoria educacional (representada pelos técnicos) e 
levou a considerar que a experiência cotidiana permanecia como um valor de legitimação para o espaço dos educadores. Paradoxalmente, a prática cotidiana, que constitui uma tarefa conservadora por natureza, coloca-se na voz dos professores primários como condição para validar as mudanças necessárias para a modernidade educativa. Observações dessa natureza motivaram reações por parte dos técnicos educacionais, descritas no texto de Amarílio Ferreira Jr. (1998). Segundo ele, Amaral Fontoura, um técnico em educação do Distrito Federal e também autor de manuais pedagógicos publicados no período, reclamava, quando do II Congresso, um "relatório básico" que estabeleceria os temas apropriados para a discussão, delimitaria o espaço e os tópicos para a palavra autorizada sobre educação, funcionando como um mecanismo de seleção dos mesmos:

Esse relatório básico seria uma espécie de "afirmação de princípios", isto é, uma exposição daqueles pontos já considerados pacíficos em educação. Tal trabalho prévio evita que algum elemento mais inocente ou menos avisado venha roubar o precioso tempo das comissões com teses pueris, afirmando cousas já sabidas por todos, como por exemplo, "as vantagens da merenda escolar", ou apresentar teses errôneas, absurdas, inqualificáveis, como por exemplo, "a entrega do ensino primário ao governo federal" (FONTOURA, Amaral. O congresso dos professores do Brasil. Revista do Ensino, Porto Alegre, 32, maio 1954. Apud FERREIRA JR., 1998, grifos nossos).

A tarefa de estabelecer o que já era considerado "ponto pacífico" em educação, ou seja, aquilo que de tão óbvio para aqueles pertencentes ao campo educacional não mereceria discussão (“teses pueris”) coube aos técnicos em educação, detentores de maior legitimidade por sua formação especializada. Trata-se, nos termos da teoria dos campos de Bourdieu (1996), do estabelecimento da doxa, ou seja, dos consensos básicos que permitem o debate e a disputa por posições de poder, em suma, do desenho do tabuleiro do jogo.

Não há notícia, na documentação obtida desse Congresso, a respeito da adoção da proposta desse técnico de ensino; porém há indícios de tentativas de disciplinar o debate que se efetivou, tendo em conta comentários presentes nas atas de reuniões da Diretoria da SUPP: a professora Helena Maia, ao relatar suas impressões do II Congresso, contava que em algumas sessões plenárias houve "debates acalorados; achou no entanto que os técnicos em educação dominaram, porém em parte os professores primários adquiriram ótimos ensinamentos."(21/02/56, grifos nossos). Embora os técnicos em educação se impusessem 
nos debates, parecem ter tido certa dificuldade para controlar a apresentação de teses, uma vez que o tema da federalização do ensino primário voltou a ser apresentado no III Congresso Nacional, realizado em 1959 em Pernambuco. Quanto a este último Congresso, consta nas atas da SUPP que:

A Profa. Helena Maia explica que o Congresso foi mais de ensino do que de professor primário, pelos assuntos estudados e debatidos, por ter ficado os postos-chave nas mãos dos técnicos cuja presença inibe o professor primário de externar suas idéias. (ATAS do III Congresso Nacional dos Professores Primários, 1959).

Essas palavras deixam claro que entre os professores primários o tema da racionalização do ensino foi pauta entre as mais importantes. Por um lado, havia a crença de que as competências técnicas permitiram superar as dificuldades da profissão, pautando as ações nos estudos científicos e especializados. Mas, por outro lado, não se pode ignorar os debates postos pela categoria docente quando ela acusou os técnicos em educação de tomarem para si a tarefa de ordenar o ensino, retirando dos professores as possibilidades de falarem e opinarem sobre seu próprio trabalho em sala de aula. Assim, a ênfase nos métodos e técnicas de ensino apresentou uma dupla faceta nos Congressos Nacionais dos Professores Primários: signos de eficácia do magistério, eles foram tomados também como formas de controle do trabalho docente e de desvalorização de sua prática cotidiana.

\section{Dos pesquisadores para os administradores: as produções dos Centros Regionais de Pesquisas Educacionais}

Os cursos oferecidos pelo Centro Regional de Pesquisas Educacionais de São Paulo (CRPE/SP) entre os anos de 1957 e 1971 a administradores do ensino primário representaram uma oportunidade ímpar para a análise do encontro entre pesquisadores educacionais e aqueles encarregados de ordenar as práticas escolares. Os textos presentes na revista mantida pelo CRPE de São Paulo, Pesquisa e Planejamento, deixam entrever, em alguns momentos, o diálogo que se estabeleceu entre os professores/supervisores e os pesquisadores educacionais, ou melhor, entre os agentes vinculados ao ensino primário e aqueles ligados à 
universidade e às instâncias de pesquisa. Nos relatórios de alguns dos cursos oferecidos, bem como em conferências ou discursos pronunciados para os alunos, é possível apreender indícios tanto da reação dos professores (na verdade, "autoridades escolares") às tentativas de mudança cientificamente fundamentadas, como das expectativas daqueles que as propunham e suas representações sobre o público ao qual dirigiam esses cursos. O tipo de relação que se estabeleceu no CRPE/SP entre esses dois grupos evidencia-se nos discursos de Fernando de Azevedo publicados no primeiro número de Pesquisa e Planejamento. Dois desses discursos constituíram a abertura e o encerramento do I Seminário sobre o Ensino Primário 5 , intitulados respectivamente "Luz nova sobre os caminhos" (AZEVEDO, 1957a) e "Verdade, vida e chama" (AZEVEDO, 1957b). No primeiro destes textos, o Centro foi apresentado como um guia a serviço do bem comum para os professores que, numa sociedade em mudança, com todos os novos desafios que surgiam, deveriam buscar novas formas de atuação, cientificamente fundamentadas. Desse modo, as reformas educacionais necessárias deixariam de ser objeto de disputa política para tornarem-se ações fundamentadas em pesquisas, com levantamentos precisos de situações reais.

As pesquisas educacionais foram apresentadas como base imprescindível para a condução de políticas educativas, tendo em vista as características da moderna sociedade industrial, superando a ineficiência e a improvisação, assinaladas como marca dos momentos anteriores. No entanto, o discurso era dirigido a administradores da educação pública com vários anos de carreira, ou seja, justamente aqueles que ou pensaram ou colaboraram com as "reformas de gabinete" - era necessário não desqualificá-los de saída, para não gerar resistências ao trabalho que seria feito no Centro. Nesse sentido, foi especialmente adequada para esse público a ressalva sociológica com relação às características da sociedade tradicional: nesta, que era "menos complexa e diferenciada, e de mais alto nível de integração" (AZEVEDO, 1957a, p. 17), as reformas educacionais baseadas na opinião tinham mais chances de alcançar seus objetivos. Por assim dizer, o improviso baseado na experiência pessoal dos legisladores era compreensível numa situação anterior, mas não seria eficiente nas novas condições, que se identificavam com o surgimento de uma "civilização de base científica e técnica" (AZEVEDO, 1957a, p. 18), com uma estrutura de classes mais complexa e diferenciada e a mudança de valores que isso implicava: era preciso, na voz dos especialistas dos CRPEs, pensar novos modos de educar.

5 O Seminário aqui referido foi uma iniciativa do CRPE/SP em convênio com as Secretarias de Educação de São Paulo e Mato Grosso, por meio do qual foram enviados professores e autoridades do ensino para discutir questões educacionais, durante o mês de julho de 1957. 
Esse argumento, que percebe o momento presente como de mudanças profundas, de passagem da sociedade brasileira tradicional para o desenvolvimento industrial, encontrava-se presente em grande parte dos artigos publicados em Pesquisa e Planejamento e constituía um discurso comum aos pesquisadores vinculados aos CRPEs. Nesse contexto, a educação da época era vista como pertencente a esse passado subdesenvolvido que se pretendia superar - os índices de exclusão escolar que as estatísticas da época mostravam comprovavam seguramente a inadequação dos métodos que se vinham utilizando até o momento. Todo esse quadro fazia ver a necessidade de uma outra forma de pensar a educação e, por conseguinte, uma nova forma de pensar o trabalho docente. Fernando de Azevedo propunha a superação da caracterização do bom professor como um "artista privilegiado" que vai agir sob "inspiração" por um conjunto de conhecimentos objetivos que asseguraria a qualquer pessoa, independentemente de suas características, um padrão mínimo de eficiência a partir do conhecimento de "técnicas educativas precisas e das bases científicas em que assentam" (AZEVEDO, 1957a, p. 22). Esse novo padrão de eficiência que se estava propondo era algo que integrava as formas anteriores de conhecimento pedagógico, baseadas principalmente na psicologia e no conhecimento sociológico aplicado ao campo da educação: "Os professores, em geral, têm se mantido até aqui indiferentes demais, se não hostis, a essa atitude crítica em face de suas idéias e de suas técnicas, a esse espírito científico que é, em última análise, espírito revolucionário" (AZEVEDO, 1957b, p. 105).

Via-se como a grande contribuição da sociologia para o ensino a possibilidade de adequar as práticas docentes à realidade nacional - o conhecimento das comunidades às quais as escolas serviam orientaria o trabalho docente. Essa maior "sensibilidade social" que o professor eficiente deveria apresentar foi exemplarmente descrita por Wilson Martins, em Pesquisa e Planejamento (1957). Esse artigo citou extensamente a obra de Fernando de Azevedo para falar do papel das ciências sociais na tarefa educativa e, ao final, deteve-se no tema da formação de professores. Esta, segundo o autor do artigo, não deveria se concentrar em aperfeiçoar os conhecimentos dos professores, ou seja, em aumentar-lhes a "cultura" e sim em fazê-los sensíveis à atualidade, em "abrir-lhes os horizontes mentais" através das ciências sociais:

A Pedagogia já chegou à perfeição de estabelecer normas suficientemente perfeitas no que se refere à coisa a ensinar, à maneira de ensiná-la e ao tratamento do noviço chamado a aprendê-la. Mas, o que a Pedagogia não pode fornecer é a inteligência criadora indispensável ao mestre, sobretudo quando tem que repetir conhecimentos elaborados por outros. A 
integração da escola na comunidade, o senso realístico que deve manter em face do seu pequeno mundo para poder transmiti-lo aos seus alunos, a compreensão dos diversos "homens brasileiros" e dos diversos Brasis que impõem, por vezes, atitudes mentais completamente diversas - tudo isso é a contribuição pessoal e intransferível do mestre na obra da educação (MARTINS, 1957, p. 50).

Falava-se de professores nesses textos, mas o público a que se dirigia parte substancial dos cursos e seminários do CRPE era composta por inspetores escolares, delegados de ensino, diretores, administradores escolares... enfim, aquele grupo que constituía os escalões médios e superiores na hierarquia do sistema de ensino brasileiro. Conforme palavras de Fernando de Azevedo, esse grupo se compunha de líderes regionais, uma "elite pedagógica esclarecida" através dos quais se daria um efeito multiplicador dos conhecimentos transmitidos no Centro, gerando a transformação necessária das práticas escolares. No entanto, em vários textos relativos a cursos para este público mencionavam-se as dificuldades e resistências encontradas - os cuidados já citados anteriormente para não ferir os brios da assistência faziam-se presentes no discurso de abertura do Curso para Delegados de Ensino. É inevitável pensar em cuidados dessa natureza quando um discurso se inicia com observações do tipo "somos estudantes por toda a vida", mas para além disso, a construção do argumento que percorre todo o texto faz pensar sobre o gênero de discordância a que responde. Durante todo o artigo, Fernando de Azevedo falava da integração entre teoria e prática educacionais, identificando os pesquisadores do CRPE com a teoria e os delegados de ensino que o ouviam com a prática.

Estamos aqui reunidos para um diálogo, que esperamos seja fecundo, entre a teoria e a prática, entre a reflexão apoiada na experiência e a pesquisa científica, numa série de conversações entre amigos, possuídos do mesmo espírito público e do mesmo amor entranhado pela educação (AZEVEDO, 1957c, p. 31).

As considerações teóricas sobre as interdependências entre teoria e prática que se seguiam a esta afirmação serviam a um argumento conciliador, que procurava integrar as contribuições daqueles que reconheciam a experiência no trato das questões de ensino como capital simbólico no campo educacional às concepções que colocavam os valores da pesquisa científica e, portanto, a formação especializada, em primeiro plano. 
Teoria e prática são elementos que a incompreensão procura dissociar, mas que afinal se completam e mutuamente se fecundam. [...] Se a técnica sem a teoria corre o perigo de esterilizar-se e de se mecanizar, a teoria sem a prática arrisca-se, também ela, perdido o contato com a realidade, a perder os seus instrumentos de controle e de verificação. [...] Mas, de outro lado, as novas reflexões teóricas e os debates à luz de idéias e teorias poderão também esclarecê-los a respeito da necessidade de revisão de conhecimentos para uma renovação das técnicas nos planos da prática do ensino, da orientação dos trabalhos escolares e da reestruturação dos serviços administrativos (AZEVEDO, 1957c, p. 32).

Ou seja, a própria forma como se estruturava o trabalho docente nesse período, a partir de valores tradicionalmente vinculados à experiência, no sentido de que um professor seria tanto mais competente quanto maior fosse o seu tempo de exercício da atividade, era um obstáculo à eficiência do ensino e, portanto, necessitava ser modificada. $O$ curioso com respeito a essas modificações que se propunham era o seu caráter de integração com relação a valores que poderiam ser identificados ao passado - não se tratava de substituir o sacerdócio pela técnica, de garantir a eficiência do sistema devido à impessoalidade do trabalho que deveria ser executado e sim de integrar a uma profunda convicção da importância do próprio trabalho os instrumentos que a pesquisa científica de cunho sociológico poderia aportar.

A formação da "personalidade" do mestre e educador, encarada sob todos os aspectos - moral, espiritual e intelectual, deve, pois, a meu ver, ascender ao primeiro plano, porque é em torno dela que gravita toda a obra de educação e dela é que partem e irradiam as mais poderosas influências, tão vivas que, decorridos os anos, elas continuam a exercer-se pela própria projeção, sobre o antigo discípulo (AZEVEDO, 1957c, p. 34-35).

Os discursos dos CRPEs aqui ilustrados a partir dos artigos encontrados em Pesquisa e Planejamento podem ser tomados como o centro que estrutura o discurso de cientificidade e racionalização técnica do trabalho docente. Foram os pesquisadores que produziram esse discurso e procuraram disseminá-lo por meio dos administradores escolares, ou seja, os profissionais que cuidavam da supervisão da prática pedagógica realizada em sala de aula. Suas vozes também foram incorporadas nos manuais pedagógicos, importantes instâncias de produção e circulação do conhecimento, pois foram livros usados na formação 
de professores primários e, portanto, das concepções de magistério construídas no início da carreira. Convém, portanto, atentar para os discursos construídos nesses livros.

\section{Dos especialistas para os futuros professores: os manuais pedagógicos}

E os manuais pedagógicos? De que maneira enfatizaram os métodos e técnicas de ensino no período que nos interessa aqui? Temos insistido nessas perguntas porque elas ganham dimensões especiais no caso desses livros, entendidos como "produções intermediárias" no campo educacional (SILVA, 2005). Esses textos foram leituras obrigatórias em Escolas Normais. Portanto, não estamos atentando para regulamentações oficiais do ensino nem para relatos de professores sobre suas experiências cotidianas. O lugar dos manuais pedagógicos foi outro, eles foram "mediadores" entre as prescrições do Estado, os saberes científicos e as práticas das salas de aula. Eles também não foram incluídos entre as obras mais reconhecidas da educação. Nota-se uma certa hierarquia na literatura da área, dividindo as produções em dois níveis: um mais legítimo, ligado aos saberes teóricos, e outro mais relacionado ao exercício do magistério (DEPAEPE, 2000). Desde quando começaram a ser escritos, em finais do século XIX, os livros de formação explicaram as ideias dos "grandes pensadores", dos movimentos pedagógicos, apresentando-se muitas vezes em seus prefácios como escritos "modestos" ou "nada originais" (SILVA, 2005). Diferentemente dos periódicos, os livros de formação não foram espaços de debate, já que criaram textos fundamentalmente explicativos. Esses títulos foram usados desde o século XIX nas mais diversas partes do mundo: em Portugal, no Brasil (SILVA, 2005) e em outros países como a França (ROULLET, 1998) e a Espanha (FERNÁNDEZ; SALVADO, 1998; PINTADO, 2000), onde houve esforços para ampliar as oportunidades escolares. Tais impressos foram leitura obrigatória, sobretudo entre aquelas pessoas que não tiveram acesso a graus mais elevados de instrução (NÓVOA, 1987) e que, para ingressarem na carreira docente, limitaram seus estudos ao âmbito das Escolas Normais ou do preparo para concurso de admissão na carreira do magistério. Os manuais explicaram as atribuições do docente, as atividades do aluno, o funcionamento das aulas, a organização dos conteúdos, os métodos didáticos. Durante o período que aqui nos interessa, que corresponde às décadas de 1950 a 1970, os títulos publicados enfatizaram os métodos e técnicas de ensino (SILVA, 2005). 
A metáfora da "pedagogia dos céus" e da "pedagogia da terra" foi emblemática de uma preocupação comum no período e apareceu num manual pedagógico publicado entre as décadas de 1950 e 1980, o Didática mínima, de Rafael Grisi (1963), um dos títulos brasileiros mais lidos por normalistas e estudantes de outros cursos de formação docente. Ao apresentar o seu livro, o autor criticou a literatura educacional por reunir produções desiguais, opondo a chamada "Pedagogia das Cátedras", aquela que, em suas palavras, anda "com a cabeça nas estrelas" e "nada tem que ver com o que se passa efetivamente todos os dias dentro das salas de aula", com a "Didática usual", caracterizada por "manter os pés no chão", ou seja, por lidar diretamente com a rotina das atividades escolares (1963, p. XI e XIII). Para Grisi, havia dois tipos de profissionais. De um lado, os "professores que, tendo tido preparação pedagógica, não se puderam valer dela para a solução dos problemas com que se defrontaram em suas relações com os alunos e, por isso, voltaram definitivamente as costas às 'teorias' dos pedagogos" (GRISI, 1963, p. XII). De outro lado, os “docentes [...] numa aprendizagem didática puramente empírica, via de regra, defeituosa mas, de qualquer modo, suficiente "para o gasto"' (GRISI, 1963, p. XII).

Sendo assim - prosseguiu o autor - era preciso encontrar uma "Didática de emergência ou de transição", uma espécie de caminho "intermediário" assumido pelo seu manual ao apresentar os saberes tidos como essenciais para a profissão docente, originariamente feito por vários pedagogos, psicólogos, biólogos, sociólogos, entre outros. Mediante a metáfora, estabeleceu-se uma hierarquia entre os autores da bibliografia selecionada e sintetizada, os quais, como sugere a analogia, dominaram a "pedagogia dos céus", e os professores em suas práticas diárias, desenvolvendo a "pedagogia da terra". Na verdade, a Didática mínima realizou uma prática comum a todos os manuais pedagógicos e é tomada aqui como um caso exemplar. Nesse sentido, foram comuns nos prefácios desses livros os termos: "compêndio", apresentado, por exemplo, em Manual de pedagogia moderna (BACKHEUSER, 1954); "coletânea" ou "texto básico". Planos e métodos de ensino transpareceram nos nomes e índices dos manuais publicados entre os anos 1950 e 1960 . Outro aspecto muito notável foi que apenas nesse momento esses livros começaram a ser assinados também por algumas professoras, embora a maior parte dos escritores tenha continuado a ser composta por homens. Isso esteve relacionado à participação feminina no mercado de trabalho e no campo educacional que, segundo Luiz Pereira (1969), em meados do século XX foi ampliada pela expansão da rede escolar pública paulista e manifestou a crescente profissionalização das mulheres. Embora elas fossem a maioria no corpo docente, encontraram-se em minoria nos cargos de direção e controle do sistema. Nos anos 1960 começou a se intensificar a profissionalização das professoras pela ascensão às posições de direção, pois, 
como explicou o autor, "a esmagadora maioria feminina no corpo docente tende a limitar cada vez mais as possibilidades de o recrutamento de diretores incidir majoritariamente numa minoria docente masculina em decréscimo" (PEREIRA, 1969, p. 103). Geralmente, essas mulheres que publicaram textos de cursos para o magistério optaram pelo regime de coautoria e trataram de questões ligadas ao trabalho em sala de aula, sugerindo procedimentos, regras e atividades a serem reproduzidas nessa situação.

Esses profissionais enfatizaram em seus textos a elaboração de planos de aula, o que eles acreditaram ser útil para o bom encaminhamento das atividades escolares. A ideia de planejamento - tema comum entre manuais pedagógicos desde finais dos anos 1940 e início dos anos 1950 - é aqui entendida antes como um ato político do que como um mero instrumento técnico, consistindo num "processo diretor, onde fossem estabelecidas metas, etapas, objetivos, índices capazes de estimular o desenvolvimento econômico do país" (LIMA, 1978, p. 107). O presidente Juscelino Kubitschek investiu na indústria nacional e estabeleceu o Programa de Metas, dentre as quais a educação constou como um dos objetivos porque se acreditou ser necessário formar profissionais aptos às modernas atividades de produção. O planejamento articulou-se a uma política governamental, sugerindo uma racionalização do ensino em nome do crescimento econômico brasileiro. Isso motivou nos autores dos manuais pedagógicos a exposição de métodos e técnicas a serem reproduzidos pelo professor no preparo e encaminhamento de suas aulas. Essa ênfase, também ilustrada na epígrafe com a qual iniciamos o presente artigo, fez da sala de aula o espaço nuclear de trabalho do professor. A docência moderna vem se consolidando, assim, em orientações para o estabelecimento de rotinas organizacionais relativamente estáveis e que até são facilmente reconhecidas entre nós.

\section{Considerações finais}

Nos discursos oficiais, dos especialistas em educação ou dos professores primários produzidos em meados do século XX, foi notável o consenso em afirmar o valor dos métodos e técnicas de ensino. Mas o próprio lugar de produção de cada um desses discursos fez surgir também divergências. Para os docentes, a perspectiva mais racional de seu trabalho poderia garantir orientações cientificamente fundamentadas e uma valorização de seu trabalho. Diferentemente, para os especialistas e administradores das escolas, os métodos e técnicas tornariam mais eficazes os esforços de ordenação do trabalho em sala de aula e 
nos sistemas de ensino. Pode-se identificar claramente, nos três contextos assinalados, a presença de um conflito entre as categorias da "teoria" e da "prática", que corresponde a lugares diferentes do campo educacional, num momento em que este vivia um processo de mudança em seus padrões de legitimidade. Trata-se de um conflito social que encontra expressão nas formas de produção e circulação do conhecimento do campo, como se vê na delimitação dos "temas autorizados" nos Congressos Nacionais de Professores Primários. Estabeleceu-se uma hierarquia, na qual tiveram primazia os "técnicos em educação" que foram também funcionários do Estado - a expressão dessa contradição encontra-se no espaço criado pelo discurso de nível intermediário dos autores dos manuais, que procuraram conciliar os dois polos do conhecimento sobre ensino.

É possível identificar no entrecruzamento dos textos tomados aqui para análise um duplo movimento: a progressiva adesão aos valores vindos de uma visão técnica do ensino como verdades inquestionáveis e uma diminuição da rejeição (ao menos pública) da teoria educacional pelos professores tradicionais, num movimento que termina por configurar um tipo diferenciado de conhecimento pedagógico. Este conhecimento foi se constituindo nos manuais de formação e não se identificou nem às "teorias" distanciadas da sala de aula nem aos elementos da vivência do trabalho cotidiano. Trata-se de uma formulação híbrida, visando ao consenso, que marcou fortemente tanto a produção na área educacional como as expectativas dos professores com relação às contribuições da pedagogia para o cotidiano escolar. Convém refletir sobre essas formas de configuração dos conhecimentos pedagógicos, pois a familiaridade de determinadas representações da docência pode conduzir a uma ideia equivocada, de que elas sejam naturais, quando na verdade correspondem a discursos construídos em meio a discussões e embates no campo educacional.

\section{REFERÊNCIAS}

ATAS do III Congresso Nacional dos Professores Primários. Pernambuco, 1959.

AZEVEDO, F. Luz nova sobre os caminhos. Pesquisa e Planejamento, n. 1, p. 13-28, jul. 1957a.

. Verdade, vida e chama. Pesquisa e Planejamento, n. 1, p. 103-108, jul. $1957 \mathrm{~b}$.

. Teoria e experiência educativa. Pesquisa e Planejamento, n. 2, p. 31-38, jul. $1957 \mathrm{c}$. 
. A transmissão da cultura. São Paulo: Melhoramentos/ MEC, 1976.

BACKHEUSER, E. Manual de pedagogia moderna. Porto Alegre: Livraria do Globo, 1954.

BOURDIEU, P. Razões práticas: sobre a teoria da ação. São Paulo: Papirus, 1996.

CATANI, D. Distâncias, vizinhanças, relações - comentários sobre os estudos sócio-histórico-comparados em educação. In: NÓVOA, A.; SCHRIEWER, J. (Ed.). A difusão mundial da escola. Lisboa: Educa, 2000. p. 143-150.

CHARTIER, R. A História Cultural. Rio de Janeiro: Difel, 1990.

CORREIA, A.; GALLEGO, R. Escolas públicas primárias em Portugal e em São Paulo: olhares sobre a organização do tempo escolar (1880-1920). Lisboa: Educa, 2004.

DEPAEPE, M. Order in progress. Bélgica: Leuven University Press, 2000.

FERNÁNDEZ, N.; SALVADO, J. Los libros y guías para el maestro. In: BENITO, A. (Dir.). Historia ilustrada del libro escolar en España de la posguerra a la reforma educativa. Madrid: Fundación Germán Sánchez Ruipérez, 1998, p. 439-468.

FERREIRA Jr., A. Sindicalismo e proletarização: a saga dos professores brasileiros. Tese (Doutorado em História Social) - FFLCH - USP. São Paulo, 1998.

GRISI, R. Didática mínima. São Paulo: Companhia Editora Nacional, 1963.

LIMA, D. Educação, Igreja e ideologia. Rio de Janeiro: Francisco Alves, 1978.

LUGLI, R. O trabalho docente no Brasil: o discurso dos Centros Regionais de Pesquisa Educacional e das entidades representativas do magistério (1950-1971). Tese (Doutorado em Educação) - USP. São Paulo, 2002.

MACHADO, N. J. O tecnicismo e a hipertrofia do psico-pedagógico. Cadernos PUC: EDUC/Cortez, n. 3, p. 11-27, mar. 1980.

MARTINS, W. O novo Emílio. Pesquisa e Planejamento, n. 1, p. 29-50, jul. 1957.

MATOS, L. A linguagem didática no ensino moderno. Rio de Janeiro: Aurora, 1960. . Sumário de didática geral. Rio de Janeiro: Aurora, 1957.

NÓVOA, A. Le temps des professeurs. Lisboa: INIC, 1987.

NÓVOA, A.; SCHRIEWER, J. (Ed.). A difusão mundial da escola. Lisboa: Educa, 2000.

NÓVOA, António. Uma educação que se diz nova. In: CANDEIAS, António; NÓVOA, António; FIGUEIRA, Manuel Henrique. Sobre a educação nova: cartas de Adolfo Lima a Álvaro Viana de Lemos (1923-1941). Lisboa: Educa, 1995. p. 25-41.

PEREIRA, L. O magistério primário numa sociedade de classes. São Paulo: Pioneira, 1969. 
PERRENOUD, P. Práticas pedagógicas, profissão docente e formação. Lisboa: Dom Quixote, 1993.

PINTADO, A. M. Los manuales de historia de la educación y la formación de los maestros (1900-1930). Historia de la educación - Revista Interuniversitaria. Universidad de Salamanca, n. 19, p. 121-139, 2000.

RIBEIRO, M. História da Educação Brasileira. Campinas: Ed. Autores Associados, 2000.

ROCHA, A. Federalização do ensino primário. Tese apresentada ao II CNPP, 1955.

ROULLET, M. Manuels de pédagogie et de psychologie dês écoles normales en France entre 1880 et 1920. These de Docteur - Université de Genève. Genève, 1998.

SILVA, V. Saberes em viagem nos manuais pedagógicos: construções da escola em Portugal e no Brasil (1870-1970). Tese (Doutorado em Educação) - USP. São Paulo, 2005.

TYACK, D. B. The one best system. Cambridge, Massachusetts, Londres: Harvard University Press, 1974.

Texto recebido em 27 de maio de 2014. Texto aprovado em 16 de julho de 2014. 